Вісник Дніпропетровського університету. Біологія. Екологія. - 2008. - Вип. 16, т. 2. - С. 147-151.

Visnyk of Dnipropetrovsk University. Biology. Ecology. - 2008. - Vol. 16, N 2. - P. 147-151.

\title{
УДК 632.938.1
}

Н. А. Рябченко, А. А. Шубин, В. Д. Малыгина, В. Г. Привалова, Е. Н. Михалева

Донечкий наџиональный университет экономики и торговли

им. М. Туган-Барановского

\section{ВИДЫ ИММУНОДЕФИЦИТА РАСТЕНИЙ К ВРЕДИТЕЛЯМ}

На основі експериментальних даних отримано системне уявлення про види імунодефіциту рослин озимої пшениці до шкідників.

N. A. Ryabchenko, A. A. Shubin, V. D. Malygina, V. G. Privalova, E. N. Mikhalyova

M. Tugan-Baranovsky Donetsk National University of Economy and Trade

\section{TYPES OF IMMUNODEFICIENCY OF PLANTS TO PESTS}

The system conception of the winter wheat's immunodeficiency to vermin is proposed on the basis of the experimental data.

\section{Введение}

Явление индуцированного снижения иммунитета растений к вредителям основывается на возникновении различных мутаций, которые являются источником их генотипической изменчивости [8]. Разработанная нами концепция иммунодефицита нашла свое отражение в интенсивных технологиях возделывания озимой пшеницы, базирующихся на широком применении пестицидов, удобрений, предпосевной стимуляции семян различного рода излучением и т. д. Установлено, что инсектициды вызывают у растений хромосомные аномалии благодаря локализованному их действию на гетерохроматиновые зоны [7]. Оказалось, что применение гербицидов на посевах злаковых культур привело к индуцированию аномалий в меиотических делениях меристематических клеток и изменению в структуре хромосом [10]. По данным А. А. Жученко [3], различные формы и дозы азотных удобрений вызывают рекомбиногенное действие в клетках, приводящее к нарушению моногибридных соотношений, изменению частоты кроссинговера, а также к восстановлению либо нарушению независимости наследования несщепленных генов.

Цель наших исследований - охарактеризовать различные виды иммунодефицита растений при воздействии вредителей.

\section{Материал и методы исследований}

Исследования проводили в 2003-2007 годах на растениях озимой пшеницы Альбатрос одесский, выращенных по интенсивной технологии возделывания. Изучали мутагенную активность, вызванную инсектицидом базудин, при помощи цитологического анализа. Временные препараты из растений озимой пшеницы, окрашенные по Фельгену с мацерацией в пектиназе, подвергали цитологическому анализу на частоту хромосомных аббераций в поздних анафазах и ранних телофазах. Тестом на мутагенную активность служили хромосомные перестройки, учитываемые в анафазе первого митоза на временных ацетокарминовых препаратах из кончиков меристематических корешков рас-

(C) Н. А. Рябченко, А. А. Шубин, В. Д. Малыгина, В. Г. Привалова, Е. Н. Михалева, 2008 
тений. Степень спонтанной гибридизации определялась на 7 сортах озимой пшеницы. Для выявления кариотипа мутантных растений пшеницы исследовали хромосомы по стандартной методике с последующим окрашиванием по Г. Макгрегору и Д. Варли [6]. Устойчивость растений озимой пшеницы к злаковым мухам оценивали по методике И. Д. Шапиро [11].

\section{Результаты и их обсуждение}

Иммунитет растений к вредителям - свойство растительного организма, выражающееся в виде адаптивных реакций на воздействие биотических факторов окружающей среды, характер которых определяется структурно-функциональным взаимодействием генов конституциональной устойчивости и экологической адаптации. Результаты проведенных исследований показали, что явление иммунодефицита характеризуется рядом видов: пестицидный, гибридологический, комплексный и др.

Пестицидный иммунодефицит. Пестициды обладают выраженным мутагенным свойством при воздействии на растительный организм [4; 5; 9]. При обработке зерна и растений озимой пшеницы базудином наблюдалось достоверное превышение спонтанного уровня мутаций (табл. 1).

Таблииа 1

Влияние базудина на мутагенез растений озимой пшеницы Альбатрос одесский

\begin{tabular}{|l|c|c|c|c|}
\hline \multirow{2}{*}{\multicolumn{1}{|c|}{ Вариант }} & \multicolumn{4}{c|}{ Типы перестроек } \\
\cline { 2 - 5 } & \multicolumn{2}{|c|}{ хромосомные } & \multicolumn{2}{c|}{ хроматидные } \\
\cline { 2 - 5 } & мосты & фрагменты & мосты & фрагменты \\
\hline Контроль (без обработки инсектицидом) & 0,19 & 0,24 & 0,36 & 0,15 \\
\hline Семена обработаны базудином & 0,31 & 0,52 & 1,87 & 0,51 \\
\hline Растения опрысканы базудином & 0,58 & 0,31 & 2,04 & 0,18 \\
\hline $\begin{array}{l}\text { Семена обработаны базудином }+ \\
\text { растения опрысканы базудином }\end{array}$ & 0,63 & 0,42 & 2,59 & 0,22 \\
\hline
\end{tabular}

Количество хромосомных перестроек в растениях озимой пшеницы в варианте с обработкой зерна базудином возросло в 1,9 раза, хроматидных - в 4,6 раза по сравнению с контролем. Опрыскивание растений озимой пшеницы этим инсектицидом обусловило такую же закономерность в увеличении типов перестроек.

Семенной материал озимой пшеницы, выращенной при широком использовании инсектицидов, характеризовался ежегодным накоплением модификаций, приводящих со временем к концентрации новых не иммунологических признаков. Проведенные исследования показали, что многолетнее применение пестицидов вызывало снижение устойчивости растений озимой пшеницы к злаковым мухам (табл. 2).

Экспериментальные данные показывают, что наряду с известным явлением «иммунодефицита», вызванного антропогенным воздействием (применение пестицидов и т. д.), разновидность которого мы назвали индуцированным, в популяциях агроценоза существует другой эффективный внутрипопуляционный механизм снижения устойчивости. Его сущность заключается в повышенной склонности сортов в сортосмесях к спонтанной гибридизации и к мутационному процессу, при котором возникают анеуплоидные формы со слабовыраженной конкурентной способностью и, как результат, устойчивостью к вредителям. Эту разновидность «иммунодефицита» мы назвали фоновой.

Фоновый иммунодефицит. Проведенными исследованиями иммунологических свойств сортов озимой мягкой пшеницы полукарликового типа в зависимости от разной степени их засорения было установлено, что сортовое засорение приводит к ускоренному снижению устойчивости растений к вредителям. Причинами интенсивного сортового засорения короткостебельных сортов являются повышенная их склонность к спонтанной 148 
гибридизации, мутационному процессу, возникновению анеуплоидных форм, а также слабовыраженная конкурентная способность растений основного сорта по отношению к сортовой примеси [1]. Способность к спонтанной гибридизации у полукарликовых форм озимой пшеницы в несколько десятков раз выше, чем у обычных сортов (табл. 3).

Таблий 2

Влияние базудина на устойчивость озимой пшеницы Альбатрос одесский к злаковым мухам

\begin{tabular}{|c|c|c|c|c|}
\hline \multirow{2}{*}{ Период } & \multirow{2}{*}{ Вариант } & \multicolumn{3}{|c|}{ Повреждено стеблей, \% } \\
\hline & & всего & главных & придаточных \\
\hline \multirow{5}{*}{2003 г. } & контроль (без обработки инсектицидом) & $3,6 \pm 0,15$ & $1,2 \pm 0,01$ & $2,4 \pm 0,03$ \\
\hline & семена обработаны базудином & $4,1 \pm 0,11$ & $0,8 \pm 0,01$ & $3,3 \pm 0,02$ \\
\hline & растения опрысканы базудином & $4,8 \pm 0,19$ & $1,5 \pm 0,02$ & $3,3 \pm 0,02$ \\
\hline & $\begin{array}{l}\text { семена обработаны базудином + } \\
\text { растения опрысканы базудином }\end{array}$ & $5,2 \pm 0,14$ & $2,1 \pm 0,02$ & $3,1 \pm 0,03$ \\
\hline & $p$ & $<0,05$ & $<0,01$ & $<0,05$ \\
\hline \multirow{5}{*}{2004 г. } & контроль (без обработки инсектицидом) & $4,2 \pm 0,09$ & $0,6 \pm 0,01$ & $3,3 \pm 0,02$ \\
\hline & семена обработаны базудином & $5,6 \pm 0,11$ & $1,4 \pm 0,02$ & $4,2 \pm 0,03$ \\
\hline & растения опрысканы базудином & $4,7 \pm 0,08$ & $1,1 \pm 0,01$ & $3,6 \pm 0,02$ \\
\hline & $\begin{array}{l}\text { семена обработаны базудином + } \\
\text { растения опрысканы базудином }\end{array}$ & $3,9 \pm 0,14$ & $0,8 \pm 0,01$ & $3,1 \pm 0,02$ \\
\hline & $p$ & $<0,05$ & $<0,05$ & $<0,01$ \\
\hline \multirow{5}{*}{2005 г. } & контроль (без обработки инсектицидом) & $6,8 \pm 0,21$ & $2,1 \pm 0,02$ & $4,7 \pm 0,03$ \\
\hline & семена обработаны базудином & $4,2 \pm 0,12$ & $1,3 \pm 0,01$ & $2,9 \pm 0,02$ \\
\hline & растения опрысканы базудином & $3,9 \pm 0,08$ & $1,1 \pm 0,01$ & $2,8 \pm 0,02$ \\
\hline & $\begin{array}{l}\text { семена, обработанные базудином + } \\
\text { растения, опрысканные базудином }\end{array}$ & $6,4 \pm 0,14$ & $2,5 \pm 0,02$ & $3,9 \pm 0,03$ \\
\hline & $p$ & $<0,05$ & $<0,05$ & $<0,05$ \\
\hline \multirow{5}{*}{2006 г. } & контроль (без обработки инсектицидом) & $5,9 \pm 0,15$ & $1,4 \pm 0,01$ & $4,5 \pm 0,03$ \\
\hline & семена обработаны базудином & $7,8 \pm 0,23$ & $2,6 \pm 0,03$ & $5,2 \pm 0,04$ \\
\hline & растения опрысканы базудином & $9,3 \pm 0,36$ & $3,8 \pm 0,02$ & $5,5 \pm 0,04$ \\
\hline & $\begin{array}{l}\text { семена, обработанные базудином + } \\
\text { растения, опрысканные базудином }\end{array}$ & $7,7 \pm 0,28$ & $2,8 \pm 0,02$ & $4,9 \pm 0,03$ \\
\hline & $p$ & $<0,05$ & $<0,01$ & $<0,05$ \\
\hline \multirow{5}{*}{2007 г. } & контроль (без обработки инсектицидом) & $7,3 \pm 0,25$ & $2,7 \pm 0,02$ & $4,6 \pm 0,03$ \\
\hline & семена обработаны базудином & $12,9 \pm 0,36$ & $4,8 \pm 0,03$ & $8,1 \pm 0,02$ \\
\hline & растения опрысканы базудином & $10,8 \pm 0,32$ & $5,2 \pm 0,03$ & $5,6 \pm 0,02$ \\
\hline & $\begin{array}{l}\text { семена, обработанные базудином + } \\
\text { растения, опрысканные базудином }\end{array}$ & $15,3 \pm 0,39$ & $4,2 \pm 0,02$ & $11,1 \pm 0,04$ \\
\hline & $p$ & $<0,05$ & $<0,01$ & $<0,01$ \\
\hline
\end{tabular}

Степень спонтанной гибридизации сортов полукарликового типа с обычными по высоте сортами и между собой при совместном произрастании (\%)

\begin{tabular}{|l|c|c|c|c|}
\hline \multirow{2}{*}{ Сорт } & \multicolumn{2}{|c|}{ С высокорослыми формами } & \multicolumn{2}{c|}{ С полукарликовыми формами } \\
\cline { 2 - 5 } & 2005 г. & 2006 г. & 2005 г. & 2006 г. \\
\hline Никония (контроль) & 0,03 & 0 & 0 & 0 \\
\hline Донецкая 46 (контроль) & 0 & 0,03 & 0 & 0 \\
\hline Полукарлик 3 & 2,5 & 3,8 & 0,2 & 0,3 \\
\hline Дончанка 3 & 2,2 & 2,7 & 0,5 & 0,6 \\
\hline Южная заря & 4,1 & 3,4 & 0,8 & 0,7 \\
\hline Обрий & 1,6 & 2,5 & 0,6 & 1,6 \\
\hline Эритроспермум 1452/86 & 9,1 & 11,2 & 2,3 & \\
\hline
\end{tabular}

Это явление объясняется пониженной пыльцеобразующей способностью и большим процентом стерильной пыльцы в плодоносящих, но слаборазвитых 3-4 цветках колоса [2]. Такие цветки в наибольшей степени подвержены чужеопылению. У этих сортов 
появляются в количестве 0,5 \% высокорослые примеси анеуплоидной природы типа обратных мутаций генов полукарликовости. В результате засорения полукарликовых форм более высокорослыми изменяется геометрическая структура короткостебельного посева, a, следовательно, и условия освещенности, микроклимат. Одной из причин резкого увеличения количества высокорослой примеси при пересевах является то, что в смешанном посеве с более высокорослыми формами полукарликовые сорта обладают значительно меньшей конкурентной способностью по отношению к ним. При сортовом засорении полукарликового сорта нарушается структура агрофитоценоза, в посеве возникают процессы, происходящие в несбалансированных популяциях и приводящие к активному формообразованию. Все это способствует существенному изменению устойчивости растений к злаковым мухам иммунного сорта за 2-3 года пересева (табл. 4).

Таблица 4

Устойчивость полукарликового сорта озимой пшеницы сорта Дончанка 3 к злаковым мухам в зависимости от количества высокорослой примеси в них

\begin{tabular}{|c|c|c|c|c|}
\hline \multicolumn{2}{|c|}{ Процент сорта в смеси } & \multicolumn{3}{|c|}{ Повреждено стеблей } \\
\hline Дончанка 3 & Донецкая 46 & всего & главных & придаточных \\
\hline 100 & - & $3,7 \pm 0,19$ & $0,5 \pm 0,01$ & $3,2 \pm 0,37$ \\
\hline 0 & 100 & $24,2 \pm 3,16$ & $9,4 \pm 0,87$ & $14,8 \pm 1,86$ \\
\hline 98 & 2 & $3,5 \pm 0,24$ & $0,8 \pm 0,01$ & $2,7 \pm 0,21$ \\
\hline 96 & 4 & $6,4 \pm 0,59$ & $1,2 \pm 0,12$ & $5,2 \pm 0,63$ \\
\hline 94 & 6 & $9,8 \pm 122$ & $3,1 \pm 0,24$ & $6,7 \pm 0,58$ \\
\hline 92 & 8 & $11,9 \pm 1,46$ & $3,6 \pm 0,26$ & $8,3 \pm 1,16$ \\
\hline 90 & 10 & $14,2 \pm 1,38$ & $4,8 \pm 0,28$ & $7,4 \pm 0,92$ \\
\hline 88 & 12 & $13,8 \pm 1,57$ & $6,2 \pm 0,49$ & $7,6 \pm 0,85$ \\
\hline 86 & 14 & $17,5 \pm 1,83$ & $7,4 \pm 0,83$ & $10,1 \pm 1,33$ \\
\hline 84 & 16 & $19,1 \pm 2,14$ & $5,9 \pm 0,51$ & $13,2 \pm 1,46$ \\
\hline 82 & 18 & $20,6 \pm 2,61$ & $8,2 \pm 0,92$ & $12,4 \pm 1,23$ \\
\hline 80 & 20 & $24,5 \pm 2,94$ & $11,4 \pm 1,49$ & $13,1 \pm 1,68$ \\
\hline 78 & 22 & $21,3 \pm 2,33$ & $9,3 \pm 1,64$ & $12,0 \pm 1,49$ \\
\hline 76 & 24 & $24,1 \pm 3,05$ & $8,5 \pm 1,18$ & $15,6 \pm 1,76$ \\
\hline 74 & 26 & $23,8 \pm 2,86$ & $10,6 \pm 1,43$ & $13,2 \pm 1,64$ \\
\hline 72 & 28 & $20,6 \pm 2,44$ & $8,3 \pm 0,96$ & $12,3 \pm 1,53$ \\
\hline 70 & 30 & $25,7 \pm 3,16$ & $9,4 \pm 1,12$ & $16,3 \pm 1,88$ \\
\hline
\end{tabular}

Таким образом, на величину спонтанной гибридизации полукарликовых сортов с другими формами существенное влияние оказывает уровень их гетерогенности по биотипному составу. Гомогенные по биотипному составу полукарликовые сорта больше склонны к спонтанной гибридизации, чем такие же полиморфные по составу сорта. У сортов, представленных одним биотипом, процесс гомозиготации системы генетического контроля, способа опыления, приводящий к замене инбридинга на кроссбридинг, происходит значительно быстрее, чем у сортов, полиморфных по составу [2]. Оказалось, что спонтанная гибридизация пшеницы - вынужденный процесс, связанный с нарушениями условий, способствующих успешному протеканию у нее генетически детерминированного типа самоопыления [1]. Спонтанные гибриды, возникающие в посеве полукарликовых сортов, имеют большую конкурентную способность по отношению к растениям основного сорта, но меньшую устойчивость к скрытностебельным вредителям.

Комплексный иммунодефицит проявляется в посевах озимой пшеницы полукарликового типа с различной степенью их сортового засорения на фоне широкого применения пестицидов и других мутагенных факторов. Результаты наших исследований показали существенное снижение устойчивости растений у сорта Дончанка 3 при засорении его высокорослым сортом Донецкая 46 на фоне пестицидных обработок (табл. 5). 
Таким образом, явление иммунодефицита растений к вредителям характеризуется достоверным снижением активности иммунологических барьеров путем нарушения в культурах экологической адаптационной способности.

Таблица 5

Устойчивость полукарликового сорта озимой пшеницы сорта Дончанка 3 к злаковым мухам в зависимости от количества высокорослой примеси на фоне пестицидных обработок

\begin{tabular}{|c|c|c|c|c|}
\hline \multicolumn{2}{|c|}{ Процент сорта в смеси } & \multicolumn{3}{|c|}{ Повреждено стеблей } \\
\hline Дончанка 3 & Донецкая 46 & всего & главных & придаточных \\
\hline 90 & 10 & $17,1 \pm 1,62$ & $6,8 \pm 1,25$ & $10,3 \pm 1,19$ \\
\hline 80 & 20 & $26,5 \pm 2,46$ & $10,4 \pm 1,38$ & $16,1 \pm 1,72$ \\
\hline 70 & 30 & $34,2 \pm 2,91$ & $11,3 \pm 1,43$ & $12,9 \pm 1,53$ \\
\hline- & - & $p<0,05$ & $p<0,05$ & $p<0,05$ \\
\hline
\end{tabular}

\section{Выводы}

Явление иммунодефицита характеризуется тремя видами (пестицидный, гибридологический и комплексный). Пестицидный стресс озимой пшеницы обуславливает хромосомные и хроматидные перестройки в растительном организме. Фоновый иммунодефицит возникает при спонтанной гибридизации сортов пшеницы полукарликового типа с обычными, которая достоверно снижает иммунологические свойства растения. Комплексный иммунодефицит проявляется в посевах озимой пшеницы полукарликового типа с различной степенью их сортового засорения на фоне применения пестицидов и других мутагенных факторов.

\section{Библиографические ссылки}

1. Боридченко Ю. А. Причины сортового засорения короткостебельных сортов озимой мягкой пшеницы // Научно-технический бюллетень ВСГИ. - Одесса, 1988. - С. 4-8.

2. Боридченко Ю. А. Популяционная изменчивость сортов мягкой пшеницы полукарликового типа и особенности их семеноводства. Автореф. дисс. ... канд. с.-х. наук. - Одесса, 1990. - 16 с.

3. Жученко А. А. Рекомбинация в эволюции и селекции / А. А. Жученко, А. Б. Король. - М.: Наука, 1985. - 400 с.

4. Куринный А. И. Исследование пестицидов как мутагенов внешней среды / А. И. Куринный, М. А. Пилинская. - К.: Наукова думка, 1976. - С. 18-28.

5. Логвиненко В. Ф. Изучение мутагенного действия некоторых пестицидов на яровую твердую пшеницу / В. Ф. Логвиненко, В. В. Моргун // Цитология и генетика. - 1978. - № 3. - С. 207-212.

6. Макгрегар Г. Методы работы с хромосомами / Г. Макгрегар, Д. Варли. - М.: Мир, 1968. - 216 с.

7. Рябченко Н. А. Факторы, снижающие устойчивость зерновых культур к злаковым мухам / Н. А. Рябченко, К. Ф. Кандаурова // Тезисы докладов республиканской конференции молодых ученых. - К.: Чабаны, 1991. - С. 49.

8. Рябченко Н. А. Эколого-генетические основы устойчивости озимой пшеницы и ярового ячменя к шведским мухам. Автореф. дисс. ... д-ра биол. наук. - С.-П., 1992. - 36 с.

9. Рябченко Н. А. Адаптогенез растений к пестицидам / Н. А. Рябченко, Н. П. Коцюбинская, Е. В. Домашнева и др. - Д.: Пороги, 2000. - 193 с.

10. Фадеева Т. С. Изменчивость сортов ячменя под действием однократных обработок посевов гербицидом 2,4-Д / Т. С. Фадеева, Г. А. Кириллова, Н. С. Немцова // Вестник Ленинградского университета. Серия биология. - 1990. - Вып. 2. - С. 87-96.

11. Шапиро И. Д. Методические рекомендации по оценке устойчивости сельскохозяйственных культур к вредителям. - Л.: ВИЗР, 1987. - 46 с.

Надійшла до редколегії 10.06.2007 